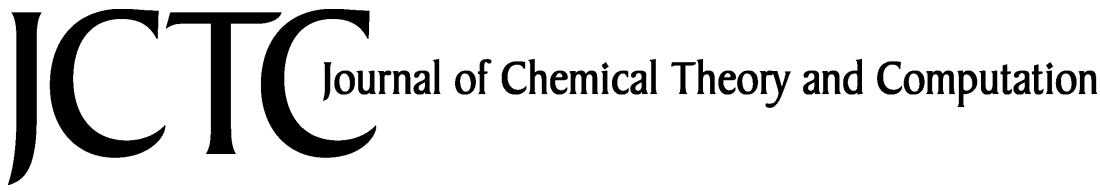

\section{Theoretical Investigation of Cheletroptic Decarbonylation Reactions}

\author{
Chin-Hung Lai ${ }^{\dagger}$ Elise Y. Li, ${ }^{\dagger}$ Kew-Yu Chen,${ }^{\dagger}$ Tahsin J. Chow, ${ }^{*}, *$ and Pi-Tai Chou ${ }^{*}, \dagger$ \\ Department of Chemistry, National Taiwan University, 106, Taipei, Taiwan, R. O. C, \\ and Institute of Chemistry, Academia Sinica, Taipei, 115, Taiwan, R.O.C.
}

Received January 10, 2006

\begin{abstract}
In this study, B3LYP is used to calculate the decarbonylation reactions of the bicyclo[2.2.1] hepta-2,5-dien-7-one (7-norbornadienone, 1 ) and its related extended fused aromatic analogues $2-5$. On the basis of our results, all of the reactions tend to proceed synchronously to expel $\mathrm{CO}$, forming the corresponding aromatic hydrocarbons. It is found that the more exothermic the reaction is, the less of a reaction barrier it needs to overcome. Moreover, upon a decrease of the reaction exothermicity, the structure of the transition state is farther away from the reactant, and the reaction barrier increases. The results agree well with the Hammond postulate as well as the Bell-Evans-Polanyi principle. Studies predict an activation energy of $27.83 \mathrm{kcal} / \mathrm{mol}$ for $\mathbf{5}$, so that the production of pentacene from compound $\mathbf{5}$ might proceed at elevated temperatures such as $400 \mathrm{~K}$.
\end{abstract}

\section{Introduction}

Since the early 1900s, it has been recognized that bicyclo[2.2.1] hepta-2,5-dien-7-one (7-norbornadienone, 1) was remarkably prone to fragmentation, losing carbon monoxide. ${ }^{1}$ The previously reported activation energy for its fragmentation to carbon monoxide and benzene was $15 \pm 2.5 \mathrm{kcal} /$ mol..$^{2,3}$ Landesberg and Sieczkowski ${ }^{4}$ suggested that $\mathbf{1}$ was destabilized by electron repulsion between the olefinic and carbonyl $\pi$ orbitals. Woodward and Hoffmann ${ }^{5}$ discussed that the decarbonylation of $\mathbf{1}$ as an orbital symmetry allowed cheletroptic reaction, which was in turn a class of pericyclic reactions. They highlighted it as a prime example of how the availability of an allowed pathway may lower the activation energy of a reaction. In this study, we have performed a systematic approach on a series of analogues of $\mathbf{1}$ by fusing various numbers of the benzene ring (see Scheme 1) and developed some discussions extracted from the results. An extension of this study that can be made is whether pentacene can be produced from the decarbonylation reaction. Pentacene is a key prototype used in organic singlecrystal field effect transistors (FETs). Interest in organic

* Corresponding author fax: +2-23695208; e-mail: chop@ ntu.edu.tw.

National Taiwan University.

$\ddagger$ Academia Sinica.

Scheme 1. Structures of Various Compounds in This Study
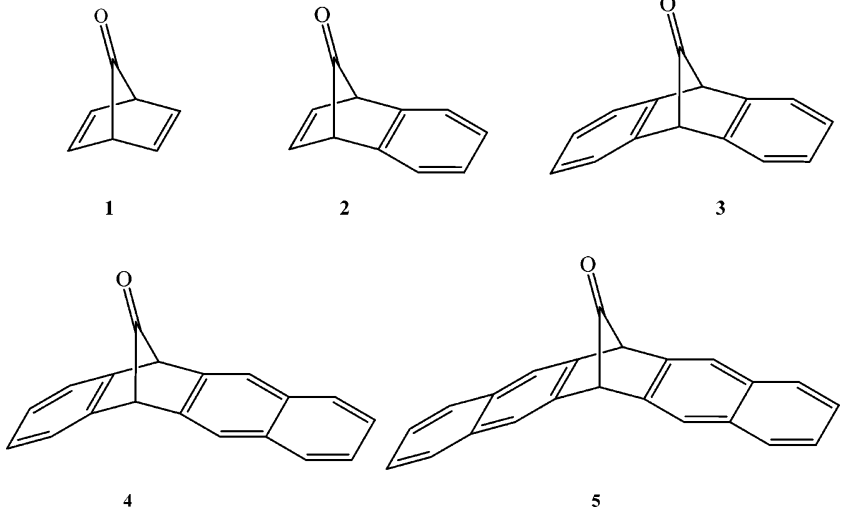

devices stems from their mechanical flexibility, their potential for interfacing to biological systems, and their ease of processing over large areas. ${ }^{6-9}$

\section{Theoretical Method}

All calculations are done with the Gaussian 03 program. ${ }^{10}$ The B3LYP functional is used with the basis set $6-31 \mathrm{G}^{*}$ (hereafter designated as B3LYP). ${ }^{11,12}$ The calculated minima and transition states (TSs) have been carefully checked by frequency analyses to examine whether the number of the 
imaginary frequency is zero or one. All mentioned energetic values are corrected for zero-point vibrational energy unless otherwise specified. All rate constants are calculated according to transition-state theory incorporating partition functions. ${ }^{13}$ In transition-state theory, the rate constant could be expressed as

$$
k=\frac{k_{\mathrm{B}} T}{h} K^{\ddagger}
$$

where $K^{\ddagger}$ denotes an equilibrium constant between the reactant and the activated complex. In statistical mechanics, the equilibrium constant $K^{\ddagger}$ could be represented by molecular partition functions of the activated complex and reactant. In Born-Oppenheimer approximation with a neglect of vibrational coupling, the molecular partition function can be factorized into its translational, rotational, vibrational, electronic, and nuclear parts. ${ }^{14}$ The translational and nuclear partition functions of the activated complex and reactant are assumed to be unchanged and can thus be canceled out. Accordingly, $K^{\ddagger}$ can be expressed as shown in eq 2 .

$$
K^{\ddagger}=\frac{q_{\mathrm{r}}^{\ddagger} q_{\mathrm{v}}^{\ddagger} q_{\mathrm{e}}^{\ddagger}}{q_{\mathrm{r}} q_{\mathrm{v}} q_{\mathrm{e}}}
$$

where the superscript $\ddagger$ gives an indication of the partition functions of the activated complex and $q_{\mathrm{r}}, q_{\mathrm{v}}$, and $q_{\mathrm{e}}$ are the rotational, vibrational, and electronic partition functions, respectively. $q_{\mathrm{v}}^{\ddagger}$ excludes the contribution of the reaction coordinate, and $q_{\mathrm{e}}$ just considers the contribution of the ground state. The critical rotational constants and vibrational frequencies for the rotational and vibrational partition functions are calculated by B3LYP. More detailed information is provided in the Supporting Information.

\section{Results and Discussion}

3.1. The Reliability of the B3LYP Results. First of all, the reliability of our B3LYP results is investigated. In Table 1, the results of B3LYP and MP2 ${ }^{15}$ with the same basis set (hereafter designated as MP2) are compared with the previous results for the cases of compounds $\mathbf{1}$ and $2 .^{2,16}$ The geometric parameters of interest for further discussion are also defined in Table 1, in which a truncated structure of the transition state is depicted as 1TS. Similar tendencies can be found between these two results. Both methods predict that upon fusing one benzene ring to the 7-norbornadienone skeleton, forming $\mathbf{2}$, the activation energy is raised and the exothermicity of the reaction is decreased in comparison to that of 1. More importantly, one could find that both MP2 and B3LYP predict similar lengths for geometric parameter a, defined in Table 1. As can be seen in Table 1, our results agree with most of the listed previous experimental and theoretical values. ${ }^{2,16}$ Thus, both results render firm support in that the reaction is synchronous rather than nonsynchronous. On the basis of these benchmark tests, we conclude that the results of B3LYP are trustworthy for dealing with the current system. Furthermore, the results for $\mathbf{1}$ calculated by the B3LYP method with various basis sets $\left(6-31 \mathrm{G}^{*}\right.$, $6-31+\mathrm{G}^{*}, 6-311 \mathrm{G}^{*}$, and $\left.6-311+\mathrm{G}^{*}\right)$ are compared and listed in Table 2, along with the data in previous literature. ${ }^{2,16}$
Table 1. B BLYP and MP2 Results for the Decarbonylation Reactions and the Transition State Geometric Structures of 1 and 2 (Energetic Values in $\mathrm{kcal} / \mathrm{mol}$, Bond Lengths in $\AA$, and Bond Angles in deg)

\begin{tabular}{|c|c|c|c|c|}
\hline & HF & B3LYP & MP2 & previous result \\
\hline \multicolumn{5}{|c|}{1} \\
\hline \multirow[t]{4}{*}{$E_{\mathrm{a}}{ }^{a}$} & 21.98 & 12.95 & 12.06 & $7.8^{b}$ \\
\hline & & & & $18^{c}$ \\
\hline & & & & $16 \pm 2.5^{d}$ \\
\hline & & & & $15.2^{e}$ \\
\hline \multirow[t]{2}{*}{$\Delta H^{f}$} & -56.10 & -39.51 & -36.98 & $-51^{c}$ \\
\hline & & & & $-32.5^{e}$ \\
\hline \multirow[t]{2}{*}{ a } & 1.970 & 1.990 & 1.986 & $1.980^{b}$ \\
\hline & & & & $1.986^{g}$ \\
\hline c & 78.85 & 78.84 & 79.21 & $80.0^{b}$ \\
\hline$d$ & 1.450 & 1.450 & 1.450 & $1.451^{g}$ \\
\hline e & 1.450 & 1.450 & 1.450 & $1.451^{g}$ \\
\hline$f$ & 1.130 & 1.150 & 1.150 & $1.170^{g}$ \\
\hline g & 115.5 & 115.6 & 115.2 & \\
\hline \multicolumn{5}{|c|}{2} \\
\hline \multicolumn{2}{|l|}{$E_{\mathrm{a}}$} & 16.44 & 15.61 & \\
\hline \multicolumn{2}{|l|}{$\Delta H$} & -28.86 & -25.72 & \\
\hline \multicolumn{2}{|l|}{$\mathrm{a}$} & 2.021 & 2.021 & \\
\hline \multicolumn{2}{|l|}{ c } & 78.81 & 78.96 & \\
\hline \multicolumn{2}{|l|}{$d$} & 1.440 & 1.430 & \\
\hline \multicolumn{2}{|l|}{ e } & 1.460 & 1.450 & \\
\hline \multicolumn{2}{|l|}{$f$} & 1.150 & 1.150 & \\
\hline \multicolumn{2}{|l|}{ g } & 116.3 & 115.8 & \\
\hline
\end{tabular}

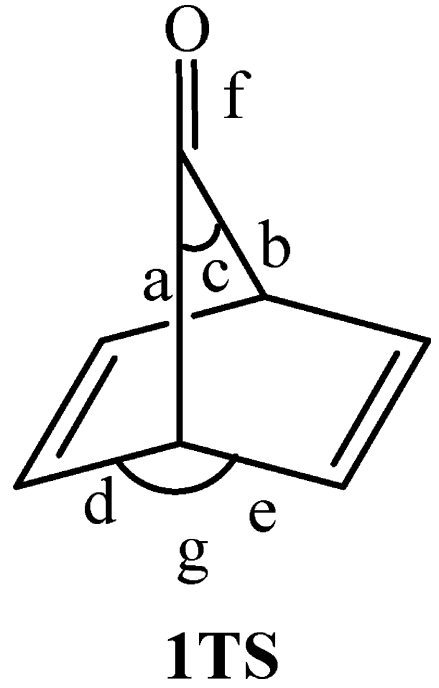

Because the reaction does not involve hydrogen atoms, the addition of second diffuse and polarization functions, that is, extra functions on hydrogen, is not necessary. This viewpoint can be supported by the results that $6-31 \mathrm{G}^{*}$ has similarities with $6-31 \mathrm{G}^{* *}$ (see Table 2) in this study. Likewise, all basis sets predict similar lengths for geometric parameter a, defined in Table 1, indicating that synchronicity of the reaction is maintained among these basis sets. In advance, we also perform the HF/6-31G* calculation and 
Table 2. Results of the Decarbonylation Reaction of 1 Using Different Basis Sets with the Same Method B3LYP (Energetic Values in $\mathrm{kcal} / \mathrm{mol}$, Bond Lengths in $\AA$ and Bond Angles in deg)

\begin{tabular}{|c|c|c|c|c|c|c|}
\hline & $6-31 G^{*}$ & $6-31 G^{* *}$ & $6-31+\mathrm{G}^{*}$ & $6-311 G^{*}$ & $6-311+\mathrm{G}^{*}$ & $\begin{array}{l}\text { previous } \\
\text { data }\end{array}$ \\
\hline \multirow[t]{4}{*}{$E_{\mathrm{a}}$} & 12.95 & 12.90 & 12.86 & 11.65 & 12.03 & $7.8^{a}$ \\
\hline & & & & & & $18^{b}$ \\
\hline & & & & & & $16 \pm 2.5^{c}$ \\
\hline & & & & & & $15.2^{d}$ \\
\hline$\Delta H$ & -39.51 & -39.48 & -41.39 & -43.23 & -42.81 & $-32.5^{d}$ \\
\hline \multicolumn{7}{|c|}{ Selected Structural Parameter of Transition State } \\
\hline \multirow[t]{2}{*}{$a^{e}$} & 1.990 & 1.990 & 1.985 & 1.970 & 1.979 & $1.980^{a}$ \\
\hline & & & & & & $1.986^{f}$ \\
\hline$c^{e}$ & 78.84 & 78.91 & 79.23 & 79.39 & 79.28 & $80.0^{a}$ \\
\hline$d^{e}$ & 1.450 & 1.450 & 1.450 & 1.450 & 1.450 & $1.451^{f}$ \\
\hline$e^{e}$ & 1.450 & 1.450 & 1.460 & 1.450 & 1.450 & $1.451^{f}$ \\
\hline$f^{e}$ & 1.150 & 1.150 & 1.150 & 1.150 & 1.150 & $1.170^{f}$ \\
\hline$g^{e}$ & 115.6 & 115.6 & 115.6 & 115.4 & 115.3 & \\
\hline
\end{tabular}

${ }^{a}$ The results were obtained by MP2/4-31G, see ref $15 .{ }^{b}$ The $\Delta G^{\ddagger}$ and $\Delta H_{\mathrm{r}}$ values are taken from ref $2 \mathrm{~b} .{ }^{c}$ The experimental $E_{\mathrm{a}}$ values are taken from NMR, see ref $2 a .{ }^{d}$ The values were calculated by MP4(SDTQ)/D95 ${ }^{\star *}$, see ref $2 \mathrm{c} .{ }^{e}$ The parameters are defined in Table $1 .{ }^{f}$ The values were calculated by MP2/6-31G*, see ref $2 \mathrm{c}$.

compare it with B3LYP, MP2, and the previous results listed in Table $12^{2,16}$ As shown in Table 1, B3LYP can handle some electron correlation because of its prediction of similar tendencies in parameters of interest, such as the enthalpy of reaction $(\Delta H)$ and the activation energy $\left(E_{\mathrm{a}}\right)$, as well as some critical bond angles and distances with respect to MP2. In summary, all of the aforementioned results support our choice of using B3LYP to calculate even larger compounds such as $\mathbf{3}-\mathbf{5}$.

3.2. The Synchronicity of the Reaction. A synchronous reaction is defined as the breakage (or formation) of several chemical bonds simultaneously during the reaction. Whether concerted pericyclic reactions occur via synchronous or nonsynchronous pathways and which theoretical or experimental criteria should be used to differentiate between them appeared to be a core issue in the past..$^{5,17-20} \mathrm{In}$ fact, ab initio calculations on pericyclic reactions have generally found synchronous transition states. ${ }^{21}$ Occasionally, nonsynchronous transition states have been found at low levels of theory, but they may disappear at higher correlated levels of theory. ${ }^{20 a, b}$ For the decarbonylation of $\mathbf{1}$, nonsynchronous transition structures have been located only at the UMNDO and UHF/STO-3G levels. But at higher levels of theory such as $(\mathrm{U}) \mathrm{HF} / 4-31 \mathrm{G}$, only the synchronous transition state has been found. In this study, we have made an attempt to locate nonsynchronous transition structures using both UB3LYP and UMP2 methods. In this attempt, different lengths for geometric parameters $\mathrm{a}$ and $\mathrm{b}$ (defined in Table 1) were set as the initial guess for the transition-state optimization. Even though such methods might be expected to favor nonsynchronous pathways, these two methods only optimized to synchronous transition structures.

3.3. The Location of the Transition State. The properties of the transition state play a critical role in chemical reactions. The calculated reaction heats and activation energies are summarized in Table 3. It was found that the exothermicity
Table 3. Activation Energies $\left(E_{\mathrm{a}}\right)$, the Heats of Formation $(\Delta H)$, and Marcus and Miller Parameters of Compounds 1-5 for the Decarbonylation Reactions

\begin{tabular}{ccccc}
\hline & $E_{\mathrm{a}}$ & $\Delta H$ & Marcus & Miller \\
\hline $\mathbf{1}$ & 12.95 & -39.51 & 0.1186 & 0.1980 \\
$\mathbf{2}$ & 16.44 & -28.86 & 0.2806 & 0.2663 \\
$\mathbf{3}$ & 22.47 & -14.29 & 0.4205 & 0.3794 \\
$\mathbf{4}$ & 24.91 & -8.731 & 0.4562 & 0.4254 \\
$\mathbf{5}$ & 27.83 & -2.502 & 0.4888 & 0.4785 \\
\hline
\end{tabular}

decreased as the number of fused benzene rings increased from $\mathbf{1}$ to $\mathbf{5}$. The tendency of the reaction heat could be rationalized by the available resonance energy after reaction. The resonance energy is usually defined as a measure of the extra stability in conjugated systems relative to their corresponding isolated double-bond analogues. The isodesmic reaction ${ }^{24}$ shown in eq 3 (taking 2 as an example) can be used to estimate the available resonance energy after the decarbonylation reaction of $\mathbf{2}, \mathbf{3}, \mathbf{4}$, or $\mathbf{5}$ relative to $\mathbf{1}$. The reaction enthalpy of eq 3 , that is, $\Delta H_{2}$, is equivalent to the difference in resonance stabilization energy between $\mathbf{1}(\mathrm{RE})_{1}$ and 2 (or 3, 4, or 5) $(\mathrm{RE})_{2}$ (or 3, 4, or 5). $\Delta H_{2}<0$ stands for $(\mathrm{RE})_{2(\text { or } 3,4,5)}>(\mathrm{RE})_{1}$ and vice versa. Accordingly, values of $\Delta H_{2}$ are calculated to be $10.66,25.22,30.78$, and 37.01 $\mathrm{kcal} / \mathrm{mol}$ for $\mathbf{2}, \mathbf{3}, \mathbf{4}$, and $\mathbf{5}$, respectively. Apparently, as the number of fused benzene rings increase from $\mathbf{1}$ to $\mathbf{5}$, the resonance stabilization energy of the corresponding products from benzene to pentacene decreases accordingly.

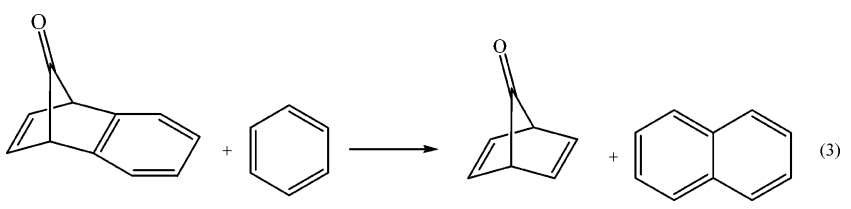

As shown in Table 3, the more exothermic the reaction is, the less of an activation barrier it has, the results of which agree well with the Hammond postulate, ${ }^{25}$ which proposes a simple qualitative correlation to relate the position of the transition state with respect to the energies of the reaction. This postulate has been proven to be valid for most chemical reactions, although some exceptions have been reported. ${ }^{26,27}$ In 1986, Birney and Berson found a good correlation between the kinetic and thermodynamic stabilities of decarbonylation of $\mathbf{1}$ and other orbital-symmetry-allowed cycloreversion reactions by plotting the activation free energy $\left(\Delta G^{\ddagger}\right)$ and the enthalpy of reaction $\left(\Delta H_{\mathrm{r}}\right){ }^{2 \mathrm{~b}}$ On the basis of a similar plot (see Figure 1), a good linear relationship $\left(R^{2}=0.9991\right)$ was found between $\Delta G^{\ddagger}$ and $\Delta H_{\mathrm{r}}$ among $\mathbf{1}-\mathbf{5}$, consistent with Birney and Benson's kinetics/thermodynamics correlation.

Several relevant models have been developed to quantitatively characterize the transition-state position, of which two are introduced here. Marcus ${ }^{28}$ suggested an expression 


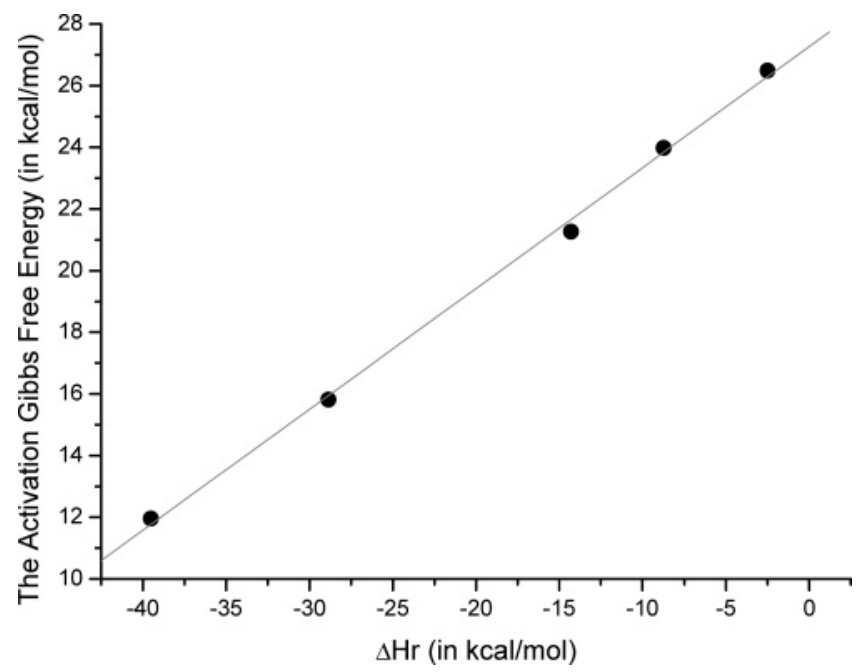

Figure 1. Linear fitting of the activation Gibbs free energy $\left(\Delta G^{\ddagger}\right)$ and the reaction heat $\left(\Delta H_{r}\right)$. Solid points are theoretical results $\left(R^{2}=0.9991\right)$

for the position of the transition state $\left(\chi^{\ddagger}\right)$, as given by eq 4 .

$$
\chi^{\ddagger}(\text { Marcus })=0.5+\frac{\Delta H_{\mathrm{r}}}{8 E_{\mathrm{a}}^{0}}
$$

where $\Delta H_{\mathrm{r}}$ is the heat of reaction and $E_{\mathrm{a}}{ }^{0}$ is the intrinsic activation energy. This equation was originally proposed to characterize electron-transfer reactions. Chen and Murdoch ${ }^{29}$ as well as others ${ }^{30}$ pointed out that eq 4 could also be used for the interpretation of other types of chemical reactions. Miller $^{31}$ devised a similar formulation for the energetic behavior of the chemical reaction, expressed in eq 5

$$
\chi^{\ddagger}(\text { Miller })=\frac{1}{2-\Delta H_{\mathrm{r}} / E_{\mathrm{a}}}
$$

For both Marcus and Miller parameters, the smaller $\chi^{\ddagger}$ value indicates that the transition state is closer to the reactant. When the value was larger (smaller) than 0.5 , the transition state was productlike (reactantlike).

Accordingly, the Marcus and Miller parameters are used to calculate the transition-state position, and the results are also listed in Table 3. Because of the exothermic reaction in the decarboxylation reaction of $\mathbf{1 - 5}$, the resulting $\chi^{\ddagger}$ values of $<0.5$ are expected. Furthermore, one can see that, as the number of fused benzene rings increases, the Marcus and Miller parameters become larger, the results from which indicate that the transition state shifts to the product side as the decarboxylation reaction takes place in compounds $\mathbf{1}-\mathbf{5}$. Furthermore, according to the Bell-Evans-Polanyi principle,$^{32}$ for closely related reactions, there exists a linear relation between $E_{\mathrm{a}}$ and $\Delta H_{\mathrm{r}}$, expressed as

$$
E_{\mathrm{a}}=A+B \Delta H_{\mathrm{r}}
$$

As depicted in Figure S1 (see the Supporting Information), a good linear relationship was observed $\left(R^{2}=0.9983\right)$ between $E_{\mathrm{a}}$ and $\Delta H_{\mathrm{r}}$ for $\mathbf{1 - 5}$, consistent with the BellEvans-Polanyi principle.

Additional firm support is provided by the structural analysis. The selected geometric parameters and the B3LYP
Table 4. Selected Geometric Parameters of 1-5 (Bond Lengths in $\AA$ and Bond Angles in deg)

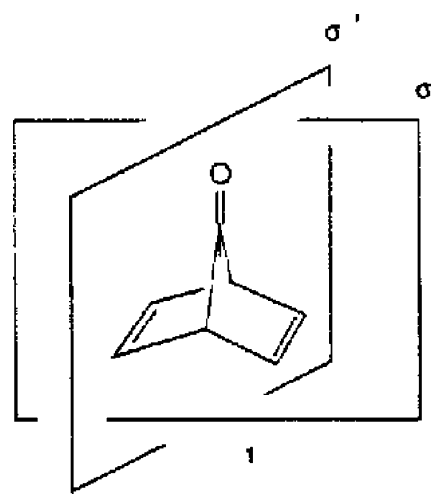

\begin{tabular}{ccccccc}
\hline & $\mathrm{a}^{a}$ & $\mathrm{c}^{a}$ & $\mathrm{~d}^{a}$ & $\mathrm{e}^{a}$ & $\mathrm{f}^{a}$ & $\mathrm{~g}^{a}$ \\
\hline $\mathbf{1}$ & 1.584 & 93.80 & 1.520 & 1.520 & 1.190 & 110.2 \\
& $1.607^{b}$ & $93.4^{b}$ & $1.533^{b}$ & $1.533^{b}$ & $1.226^{b}$ & \\
& $1.575^{c}$ & & $1.528^{c}$ & $1.528^{c}$ & $1.193^{c}$ & \\
& $1.580^{d}$ & & $1.512^{d}$ & $1.512^{d}$ & $1.201^{d}$ & \\
$\mathbf{2}$ & 1.578 & 94.86 & 1.520 & 1.520 & 1.190 & 109.1 \\
$\mathbf{3}$ & 1.574 & 95.78 & 1.520 & 1.520 & 1.190 & 108.4 \\
$\mathbf{4}$ & 1.572 & 96.05 & 1.520 & 1.520 & 1.190 & 108.1 \\
$\mathbf{5}$ & 1.570 & 96.25 & 1.520 & 1.510 & 1.190 & 108.1 \\
\hline
\end{tabular}

${ }^{a}$ The parameters are defined in Table 1, and the geometry is optimized under a Cs symmetry. The $\sigma$ planes in 1-5 are defined above (taking 1 as an example). Note that $\mathbf{2}$ and $\mathbf{4}$ have no $\sigma^{\prime}$ plane. ${ }^{b}$ The values were calculated by MP2/4-31G, see ref $15 .{ }^{c}$ The values were calculated by MNDO/3, see ref $21 .{ }^{d}$ The values were calculated by MP2/6-31G*, see ref 2c.

results of 1-5 are extracted and summarized in Table 4 . Some previous results for $\mathbf{1}$ are also listed in Table 4 for comparison..$^{2,16,22}$ One can promptly see that when the number of fused benzenes on either side of 7-norbornadienone increases, that is, from $\mathbf{1}$ to $\mathbf{5}$, the geometry of the 7-norbornadienone skeleton changes only slightly, even for the unsymmetric analogues $\mathbf{2}$ and $\mathbf{4}$. Geometric parameter a decreases slightly as the number of fused benzenes on either side of 7-norbornadienone increases. Apparently, as the decarbonylative reaction becomes more favorable, geometric parameter $\mathrm{a}$ or $\mathrm{b}$ increases accordingly. This trend agrees with the previous discussions about the retro Diels-Alder reaction and cheletropic fragmentation. ${ }^{33}$ These reactions have been proven in accord with the structure correlation principle of Dunitz et al. ${ }^{34}$ The structure correlation principle suggests that the structures of molecules can show distortions along a reaction coordinate, but only when the electronic factors that stabilize the transition state are present in an appropriate ground-state geometry. This is indeed a corollary of the Hammond postulate and of the Bell-Evans-Polanyi principle. Table 5 lists some critical bond distances and angles for the transition states of $\mathbf{3 - 5}$ (also see Table 1 for 1 and 2). In comparison, it was found that the change of the $\mathrm{O}=\mathrm{C} \cdots \mathrm{C}$ bonding distance between the reactant and the corresponding transition state increases with an increase in the number of fused benzenes from $\mathbf{1}$ to $\mathbf{5}$ (see Table 5). The results clearly show that the structure of the transition state is shifted to the product once the exothermicity of the decarboxylation reaction is decreased from $\mathbf{1}$ to $\mathbf{5}$, accompanied by an increase of the activation energy. 
Table 5. B3LYP Results for the Decarbonylation Reactions and the Transition State Geometric Structures of 3-5 (Energetic Values in $\mathrm{kcal} / \mathrm{mol}$, Bond Lengths in $\AA$, and Bond Angles in deg)

\begin{tabular}{lccc}
\hline & $\mathbf{3}$ & $\mathbf{4}$ & $\mathbf{5}$ \\
\hline$E_{\mathrm{a}}$ & 22.47 & 24.91 & 27.83 \\
$\Delta H$ & -14.29 & -8.731 & -2.502 \\
$\mathrm{a}^{a}$ & 2.098 & 2.120 & 2.156 \\
$\mathrm{c}^{a}$ & 77.00 & 76.60 & 75.73 \\
$\mathrm{~d}^{a}$ & 1.440 & 1.440 & 1.440 \\
$\mathrm{e}^{a}$ & 1.440 & 1.450 & 1.440 \\
$\mathrm{f}^{a}$ & 1.150 & 1.150 & 1.150 \\
$\mathrm{~g}^{a}$ & 117.2 & 117.6 & 117.9 \\
\hline
\end{tabular}

a The parameters are defined in Table 1.

Table 6. Calculated Rate Constants $\left(\mathrm{s}^{-1}\right)$ of the Cheletroptic Decarbonylation Reactions for Compounds 1-5

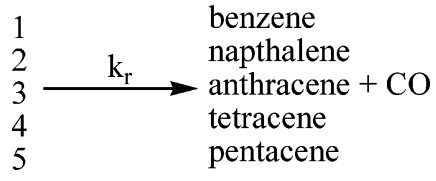

\begin{tabular}{rrrrr}
\hline & $k_{\mathrm{r}}$ at $200 \mathrm{~K}$ & $k_{\mathrm{r}}$ at $250 \mathrm{~K}$ & $k_{\mathrm{r}}$ at $300 \mathrm{~K}$ & $k_{\mathrm{r}}$ at $400 \mathrm{~K}$ \\
\hline $\mathbf{1}$ & $6.014 \times 10^{1}$ & $1.250 \times 10^{4}$ & $4.196 \times 10^{5}$ & $3.601 \times 10^{7}$ \\
& $4.62 \times 10^{-4} \mathrm{a}$ & & & \\
$\mathbf{2}$ & $1.020 \times 10^{-5}$ & $5.682 \times 10^{-2}$ & $1.876 \times 10^{1}$ & $2.843 \times 10^{4}$ \\
$\mathbf{3}$ & $6.429 \times 10^{-12}$ & $7.836 \times 10^{-7}$ & $2.043 \times 10^{-3}$ & $4.163 \times 10^{1}$ \\
& & $2.39 \times 10^{-5} \mathrm{~b}$ & \\
$\mathbf{4}$ & $9.012 \times 10^{-15}$ & $3.729 \times 10^{-9}$ & $2.202 \times 10^{-5}$ & 1.253 \\
$\mathbf{5}$ & $8.814 \times 10^{-18}$ & $1.649 \times 10^{-11}$ & $2.667 \times 10^{-7}$ & $5.367 \times 10^{-2}$ \\
\hline \multicolumn{5}{l}{ a The experimental result at $213 \mathrm{~K}$, see ref 2a. ${ }^{b}$ The experimental } \\
result at 298 K, see ref 35.
\end{tabular}

3.4. The Rate Constants. In 1979, Irie and Tanida reported the effect of the electron-withdrawing group, $\mathrm{NO}_{2}$, on the decarbonylation rate of compound $\mathbf{3}$ and found that the reaction rate increased as the number of $\mathrm{NO}_{2}$ groups on the benzene increased. The decarbonylation rates for compound 3 in dioxane were $2.39 \times 10^{-5}, 6.64 \times 10^{-5}$, and $1.45 \times 10^{-4} \mathrm{~s}^{-1}$ when the number of $\mathrm{NO}_{2}$ groups was zero, one, and two at $25^{\circ} \mathrm{C}$, respectively. ${ }^{35}$ In this study, we make an attempt to calculate the decarboxylation reaction rate constant according to the transition-state theory (see the section on the theoretical method). ${ }^{13}$ Details of the derivation of rate constants listed in Table 6 are provided in the Supporting Information. At the ambient temperature of 300 $\mathrm{K}$, the rate of decarboxylation for $\mathbf{1 - 5}$ is on the order of 4.2 $\times 10^{5}, 1.9 \times 10^{1}, 2.0 \times 10^{-3}, 2.2 \times 10^{-5}$, and $2.7 \times 10^{-7}$ $\mathrm{s}^{-1}$, respectively. For $\mathbf{1}$, the experimental value of $k=4.62$ $\times 10^{-4} \mathrm{~s}^{-1}$, deduced from a half-life of $25 \mathrm{~min}$ at $213 \mathrm{~K},{ }^{2 \mathrm{a}}$ is somewhat smaller than the $6.014 \times 10^{1} \mathrm{~s}^{-1}$ at $200 \mathrm{~K}$ calculated by the theoretical approach. This discrepancy may be due to the fact that transition-state theory neglects the probability of the backward direction of the reaction. Furthermore, solvation effects may play a major role, which is not considered in the current approach.

Nevertheless, the results indicate a minor to negligible degree of decomposition for $\mathbf{4}$ and $\mathbf{5}$ at $300 \mathrm{~K}$, whereas $\mathbf{1}$ is readily decomposed. The results are in qualitative agreement with the existing experimental evidence, ${ }^{1-3}$ which reports that the optimal temperature needed to observe decarbonylation reactions for $\mathbf{1}$ and $\mathbf{3}$ is 195 and $300 \mathrm{~K}$, respectively. If one anticipates the production of pentacene by the cheletroptic decarbonylation reaction of $\mathbf{5}$, a temperature of $400 \mathrm{~K}$, in which the rate of reaction is calculated to be 5.4 $\times 10^{-2} \mathrm{~s}^{-1}$, may serve as an optimal experimental condition. At this elevated temperature, the disadvantage for $\mathbf{5}$ seems to be the result of its small exothermic reaction with $\Delta H$ of only $-2.502 \mathrm{kcal} / \mathrm{mol}$. Nevertheless, because the product $\mathrm{CO}$ is in the gas phase at, for example, $1 \mathrm{~atm}$ and $400 \mathrm{~K}$, the equilibrium should favor pentacene formation according to Le Châtelier's principle.

\section{Conclusion}

In conclusion, we have reported a systematic approach on the cheletroptic decarbonylation reaction of $\mathbf{1}-\mathbf{5}$. The results clearly conclude that the thermal cheletroptic decarbonylation reaction tends to proceed synchronously for $\mathbf{1 - 5}$. We are particularly interested in the decarbonylation of compound 5 in producing pentacene. In view of the FET application, although thermally generated pentacene could be made by retro Diels-Alder reaction, ${ }^{36-39}$ side products are unavoidable and may exist as the impurity in the film. Alternatively, photolysis of the pentacene precursor, generating pentacene, has been reported. However, the product, that is, pentacene, is also subject to photolysis. ${ }^{39,40}$ Accordingly, $\mathbf{5}$ may serve as a prototypical pentacene precursor for organic field-effect transistors because its thermally activated process to produce pentacene is feasible under an elevated temperature of, for example, $400 \mathrm{~K}$. Our results also draw a conclusion in that, as the number of fused benzene rings on either side of 7-norbornadienone increases, that is, from $\mathbf{1}$ to $\mathbf{5}$, the corresponding $E_{\mathrm{a}}$ and the endothermicity of the reaction both increase, and the structure of the transition state leans toward the product side. This tendency can be well-described by the Hammond postulate as well as the Bell-Evans-Polanyi principle.

Acknowledgment. We are grateful to the National Center for High-Performance Computing of Taiwan for allowing us generous amounts of computing time. We also thank the National Science Council for financial support and Prof. Hu of National Chung Cheng University for his kind support in the calculation of rate constants.

Supporting Information Available: Figure S1, giving the linear fitting of activation energy $\left(E_{\mathrm{a}}\right)$ and the reaction heat $\left(\Delta H_{\mathrm{r}}\right)$, and the detailed method of deriving rate constants are available free of charge via the Internet at http:// pubs.acs.org.

\section{References}

(1) (a) Dilthey, W.; Schommer, W.; Trosken, O. Ber. Dtsch. Chem. Ges. 1933, 66, 1627. (b) Ogliaruso, M. A.; Romanelli, M. G.; Becker, E. I. Chem. Res. 1965, 65, 261. (c) Allen, C. F. H.; Van Allan, J. J. Am. Chem. Soc. 1942, 64, 1260. (d) Fieser, L. F.; Fieser, M. Organic Experiments; D. C. Heath and Co.: Boston, MA, 1964; pp 303-317. (e) Bartlett, P. D.; Giddings, W. P. J. Am. Chem. Soc. 1960, 82, 1240. (f) 
Story, P. R.; Fahrenholtz, S. R. J. Am. Chem. Soc. 1964, 86, 1270. (g) Wilt, J. W.; Chenier, P. J. J. Org. Chem. 1970, 35, 1562. (h) Gassman, P. G.; Aue, D. H.; Patton, D. S. J. Am. Chem. Soc. 1964, 86, 4211. (i) Hoffmann, R. W.; Hauser, H. Tetrahedron 1965, 21, 891. (j) Lemal, D. M.; Gosselink, E. P.; Adult, A. Tetrahedron Lett. 1964, 579. (k) Lemal, D. M.; Gosselink, E. P.; McGregor, S. D. J. Am. Chem. Soc. 1966, 88, 582. (1) Halton, B.; Battiste, M. A.; Rehberg, R.; Deyrup, C. L.; Brennan, M. E. J. Am. Chem. Soc. 1967, 89, 5964. (m) Zhang, J.; Ho, D. M.; Pascal, R. A., Jr. J. Am. Chem. Soc. 2001, 123, 10919. (n) Warrener, R. N.; Harrison, P. A. Molecules 2001, 6, 353. (o) Tobe, Y.; Kubota, K.; Naemura, K. J. Org. Chem. 1997, 62, 3430. (p) Plummer, B. F.; Currey, J. A.; Russell, S. J.; Steffen, L. K.; Watson, W. H.; Bourne, S. A. Struct. Chem. 1995, 6, 167. (q) Simpson, C. J. S. M.; Price, J.; Holmes, G.; Adam, W.; Martin, H.-D.; Bish, S. J. Am. Chem. Soc. 1990, 112, 5089.

(2) (a) Birney, D. M.; Berson, J. A. J. Am. Chem. Soc. 1985, 107, 4553. (b) Birney, D. M.; Berson, J. A. Tetrahedron 1986, 42, 1561. (c) Birney, D. M.; Ham, S.; Unruh, G. R. J. Am. Chem. Soc. 1997, 119, 4509.

(3) LeBlanc, B. F.; Sheridan, R. S. J. Am. Chem. Soc. 1985, 107, 4554.

(4) (a) Landesberg, J. M.; Sieczkowski, J. J. Am. Chem. Soc. 1968, 90, 1655. (b) Landesberg, J. M.; Sieczkowski, J. J. Am. Chem. Soc. 1969, 91, 2120. (c) Landesberg, J. M.; Sieczkowski, J. J. Am. Chem. Soc. 1971, 93, 972.

(5) Woodward, R. B.; Hoffmann, R. W. The Conservation of Orbital Symmetry; Academic Press: New York, 1970.

(6) Peumans, P.; Uchida, S.; Forrest, S. R. Nature 2003, 425, 158.

(7) Volkel, A. R.; Street, R. A.; Knipp, D. Phys. Rev. B: Condens. Matter Mater. Phys. 2002, 66, 195336.

(8) Campbell, I. H.; Smith, D. L. Solid State Phys. 2001, 55, 1.

(9) Nelson, S. F.; Lin, Y. Y.; Gundlach, D. J. Appl. Phys. Lett. 1998, 72, 1854.

(10) Frisch, M. J.; Trucks, G. W.; Schlegel, H. B.; Scuseria, G. E.; Robb, M. A.; Cheeseman, J. R.; Montgomery, J. A.; Vreyen, T., Jr.; Kudin, K. N.; Burant, J. C.; Millam, J. M.; Iyengar, S. S.; Tomasi, J.; Barone, V.; Mennucci, B.; Cossi, M.; Scalmani, G.; Rega, N.; Petersson, G. A.; Nakatsuji, H.; Hada, M.; Ehara, M.; Toyota, K.; Fukuda, R.; Hasegawa, J.; Ishida, M.; Nakajima, T.; Honda, Y.; Kitao, O.; Nakai, H.; Klene, M.; Li, X.; Knox, J. E.; Hratchian, H. P.; Cross, J. B.; Adamo, C.; Jaramillo, J.; Gomperts, R.; Stratmann, R. E.; Yazyev, O.; Austin, A. J.; Cammi, R.; Pomelli, C.; Octhterski, J. W.; Ayala, P. Y.; Morokuma, K.; Voth, G. A.; Salvador, P.; Dannenberg, J. J.; Zakrzewski, V. G.; Dapprich, S.; Daniels, A. D.; Strain, M. C.; Farkas, O.; Malick, D. K.; Rabuck, A. D.; Raghavachari, K.; Foresman, J. B.; Ortiz, J. V.; Cui, Q.; Baboul, A. G.; Clifford, S.; Cioslowski, J.; Stefanov, B. B.; Liu, G.; Liashenko, A.; Piskorz, P.; Komaromi, I.; Martin, R. L.; Fox, D. J.; Keith, T.; Al-Laham, M. A.; Peng, C. Y.; Nanayakkara, A.; Challacombe, M.; Gill, P. M. W.; Johnson, B.; Chen, W.; Wong, M. W.; Gonzalez, C.; Pople, J. A. Gaussian 03, revision C.02; Gaussian, Inc.: Pittsburgh, PA, 2004.

(11) (a) Becke, A. D. Phys. Rev. A: At., Mol., Opt. Phys. 1988, 38, 3098. (b) Lee, C.; Yang W.; Parr, R. G. Phys. Rev. B: Condens. Matter Mater. Phys. 1988, 37, 785.

(12) Ditchfield, R.; Hehre, W. J.; Pople, J. A. J. Chem. Phys. 1971, 54, 724 .
(13) (a) Gilbert, R. G.; Smith, S. C. Theory of Unimolecular and Recombination Reactions; Blackwell Scientific Publications: Oxford, U. K., 1990. (b) Truhlar, D. G.; Garrett, B. C.; Klippenstein, S. J. J. Phys. Chem. 1996, 100, 12771. (c) Robertson, S. H.; Wagner, A. F.; Wardlaw, D. M. J. Chem. Phys. 1995, 103, 2917. (d) Holbrook, K. A.; Pilling, M. J.; Robertson, S. H. Unimolecular Reactions, 2nd ed.; John Wiley \& Sons: Chichester, U. K., 1996.

(14) (a) Zhang, M.; Huang, Z.; Lin, Z. J. Chem. Phys. 2005, 122, 134313. (b) Cramer, C. J. Essentials of Computational Chemistry: Theories and Models; John Wiley \& Sons: Chichester, U. K., 2002.

(15) Head-Gordon, M.; Pople, J. A.; Frisch, M. J. Chem. Phys. Lett. 1988, 153, 503.

(16) Birney, D. M.; Wiberg, K. B.; Berson, J. A. J. Am. Chem. Soc. 1988, 110, 6631.

(17) (a) Hoffmann, R. W.; Woodward, R. B. J. Am. Chem. Soc. 1965, 87, 2046. (b) Fukui, K.; Yonezawa, T.; Nagata, C.; Shingu, H. J. Chem. Phys. 1954, 22, 1433. (c) Salem, L. J. Am. Chem. Soc. 1968, 90, 543, 553. (d) Longuet-Higgins, H. C.; Abrahamson, E. W. J. Am. Chem. Soc. 1965, 87, 2045. (e) Van der Lugt, W. T. A. M.; Oosterhoff, L. J. J. Am. Chem. Soc. 1969, 91, 6042.

(18) Dewar, M. J. S. J. Am. Chem. Soc. 1984, 106, 209.

(19) (a) Dewar, M. J. S.; Pierini, A. B. J. Am. Chem. Soc. 1984, 106, 203. (b) Gajewski, J. J.; Peterson, K. B.; Kagel, J. R. J. Am. Chem. Soc. 1987, 109, 5545. (c) Huisgen, R. J. J. Org. Chem. 1976, 41, 403. (d) Firestone, R. A. J. Org. Chem. 1972, 37, 2181. (e) Houk, K. N. J. Am. Chem. Soc. 1981, 103, 2436. (f) Taagepera, M.; Thornton, E. R. J. Am. Chem. Soc. 1972, 94, 1168. (g) Tolbert, L. M.; Ali, M. B. J. Am. Chem. Soc. 1984, 106, 3806.

(20) (a) Mclver, J. W., Jr. Acc. Chem. Res. 1974, 7, 72. (b) McIver, J. W., Jr. J. Am. Chem. Soc. 1972, 94, 4782.

(21) (a) Osamura, Y.; Kato, S.; Morokuma, K.; Feller, D.; Davidson, E. R.; Borden, W. T. J. Am. Chem. Soc. 1984, 106, 3362. (b) Bernardi, F.; Bottoni, A.; Robb, M. A.; Field, M. J.; Hiller, I. H.; Guest, M. F. J. Chem. Soc., Chem. Commun. 1985, 1051. (c) Houk, K. N.; Lin, Y. T.; Brown, F. K. J. Am. Chem. Soc. 1986, 108, 554. (d) Ortega, M.; Oliva, A.; Lluch, J. M.; Bertram, J. Chem. Phys. Lett. 1983, 102, 317. (e) Burke, L. A.; Leroy, G. G.; Sana, M. Theor. Chim. Acta 1975, 40, 313. (f) Burke, L. A.; Leroy, G. G. Theor. Chim. Acta 1977, 44, 219. (g) Brown, F. K.; Houk, K. N. Tetrahedron Lett. 1984, 4609. (h) Townshend, R. E.; Ramunni, G.; Segal, G.; Hehre, W. J.; Salem, L. J. Am. Chem. Soc. 1976, 98, 2190. (i) Dewar, M. J. S.; Ford, G. P.; McKee, M. L.; Rzepa, H. S.; Wade, L. E. J. Am. Chem. Soc. 1977, 99, 5069.

(22) Dewar, M. J. S.; Chantranupong, L. J. Am. Chem. Soc. 1983, 105,7152 .

(23) (a) Pople, J. A.; Nesbet, R. K. J. Chem. Phys. 1954, $21,571$. (b) McKee, M. L. J. Am. Chem. Soc. 1985, 107, 1900.

(24) Wiberg, K. B.; Hadad, C. M.; Rablen, P. A.; Cioslowski, J. J. Am. Chem. Soc. 1992, 114, 8644.

(25) Hammond, G. S. J. Am. Chem. Soc. 1955, 77, 334.

(26) Colthurst, M. J.; Williams, A. J. Chem. Soc., Perkin Trans. 2 1997, 1493.

(27) Lopez, X.; Dejaegere, M.; Karplus, M. J. Am. Chem. Soc. 2001, 123, 11755.

(28) Marcus, R. A. J. Chem. Phys. 1968, 72, 891. 
(29) Chen, M. Y.; Murdoch, J. R. J. Am. Chem. Soc. 1989, 108, 4735 .

(30) Lee, W. T.; Masel, R. I. J. Phys. Chem. A 1998, 102, 2332.

(31) Miller, A. R. J. Am. Chem. Soc. 1978, 100, 1984.

(32) Jencks, W. P. Chem. Rev. 1985, 85, 511.

(33) (a) Pool, B. R.; White, J. M. Org. Lett. 2000, 2, 3505. (b) Wei, H.-X.; Zhou, C.; Ham, S.; White, J. M.; Birney, D. M. Org. Lett. 2004, 6, 4289. (c) Unruh, G. R.; Birney, D. M. J. Am. Chem. Soc. 2003, 125, 8529.

(34) (a) Bürgi, H. B.; Dunitz, J. D.; Shefter, E. J. Am. Chem. Soc. 1973, 95, 5065. (b) Jones, P. G.; Kirby, A. J. J. Chem. Soc., Chem. Commun. 1979, 288. (c) Bürgi, H. B.; Dunitz, J. D. Acc. Chem. Res. 1983, 16, 153.

(35) Irie, T.; Tanida, H. J. Org. Chem. 1979, 44, 1002.
(36) Herwig, P. T.; Mullen, K. Adv. Mater. 1999, 11, 480.

(37) Afzali, A.; Dimitrakopoulos, C. D.; Breen, T. L. J. Am. Chem. Soc. 2002, 124, 8812.

(38) Weidkamp, K. P.; Afzali, A.; Tromp, R. M.; Hamers, R. J. J. Am. Chem. Soc. 2004, 126, 12740.

(39) Uno, H.; Yamashita, Y.; Kikuchi, M.; Watanabe, H.; Yamada, H.; Okujima, T.; Ogawa, T.; Ono, N. Tetrahedron Lett. 2005, 46, 1981.

(40) Yamada, H.; Yamashita, Y.; Kikuchi, M.; Watanabe, H.; Okujima, T.; Uno, H.; Ogawa, T.; Ohara, K.; Ono, N. Chem.-Eur. J. 2005, 11, 6212.

CT0600130 